\title{
Nivolumab-induced hypophysitis followed by acute-onset type 1 diabetes with renal cell carcinoma: a case report
}

\author{
Fumi Kikuchi ${ }^{1}{ }^{2 *}$, Takanobu Saheki ${ }^{1}$, Hitomi Imachi ${ }^{1}$, Toshihiro Kobayashi ${ }^{1}$, Kensaku Fukunaga $^{1}$, Tomohiro Ibata ${ }^{1}$, \\ Seisuke Sato ${ }^{1}$, Natsuki Ban ${ }^{1}$, Jingya Lyu ${ }^{1}$, Salimah Japar ${ }^{1}$ and Koji Murao ${ }^{1}$
}

\begin{abstract}
Background: Immune checkpoint inhibitors have recently become widely used for the management of advanced cancer patients. During the development of immune checkpoint inhibitors (ICPIs), it was quickly recognized that they are associated with autoimmune or autoinflammatory side effects. These toxicities are known as immune-related adverse events (irAEs): common endocrine irAEs include hypophysitis and thyroid dysfunction, and uncommon irAEs include type 1 diabetes mellitus (T1DM).
\end{abstract}

Case presentation: A 62-year-old Japanese man with metastatic renal cell carcinoma was treated with sunitinib followed by the 10th cycle of treatment with the ICPI nivolumab. He had already had thyroiditis and hypophysitis due to these anti-cancer drugs. On admission, he showed an extremely elevated plasma glucose level $(601 \mathrm{mg} / \mathrm{dl})$ and a low C-peptide level, and was diagnosed with acute T1DM. The patient was treated with intravenous fluid infusion and continuous insulin infusion. On the second day, he was switched to multiple daily injections of insulin therapy. Since these treatments, his blood glucose levels have been stable and he has been treated with an additional 10 ICPI treatments for renal cell carcinoma for over a year.

Conclusions: Treatment with ICPIs is expected to increase in the future. There may be cases in which their use for cancer treatment is inevitable despite the side effects. As long as treatment with ICPI continues, multiple side effects can be expected in some cases. It is important to carefully observe the side effects that occur during ICPI treatment and to provide appropriate treatment for each side effect.

Keywords: Immune checkpoint inhibitor, Hypophysitis, Acute type 1 diabetes mellitus, Immune-related adverse events, Nivolumab

\section{Background}

The efficacy of immune checkpoint inhibitors (ICPIs) has led to their widespread use for the management of advanced cancer patients. Nivolumab is a typical ICPI that is an anti-programmed cell death protein 1 (PD-1)

\footnotetext{
*Correspondence: taffumi1020@gmail.com

1 Department of Endocrinology and Metabolism, Faculty of Medicine,

Kagawa University, 1750-1, Miki-cho, Kita-gun, Takamatsu, Kagawa

761-0793, Japan

Full list of author information is available at the end of the article
}

antibody designed to promote an immunologic reaction against cancer cells including melanoma, non-small cell lung cancer, and renal cell carcinoma (RCC) by blocking the activation of the PD-1-mediated pathway [1]. The PD-1 protein is a cell-surface molecule on $T$ cells that prevents the activation of antigen-specific $\mathrm{T}$ cells, including those directed against tumors. During the development of ICPIs, it was quickly recognized that they are associated with autoimmune or autoinflammatory side effects [2]. These toxicities are known as immune-related adverse events (irAEs): common endocrine irAEs include original author(s) and the source, provide a link to the Creative Commons licence, and indicate if changes were made. The images or other third party material in this article are included in the article's Creative Commons licence, unless indicated otherwise in a credit line to the material. If material is not included in the article's Creative Commons licence and your intended use is not permitted by statutory regulation or exceeds the permitted use, you will need to obtain permission directly from the copyright holder. To view a copy of this licence, visit http://creativecommons.org/licenses/by/4.0/. The Creative Commons Public Domain Dedication waiver (http://creativeco mmons.org/publicdomain/zero/1.0/) applies to the data made available in this article, unless otherwise stated in a credit line to the data. 
hypophysitis and thyroid dysfunction, and uncommon irAEs include type 1 diabetes mellitus (T1DM). The factors that predict irAEs remain unclear. ICPI-related hypophysitis is frequently (up to $17 \%$ of cases) associated with ipilimumab, an anti-cytotoxic $\mathrm{T}$ lymphocyte-associated antigen-4 (CTLA-4) antibody, but hypophysitis is an extremely rare event $(<1 \%)$ in patients treated with other ICPIs, such as nivolumab [3]. In contrast, nivolumabrelated T1DM reportedly manifests as fulminant type 1 diabetes mellitus (FT1DM), which is an emergency condition, as patients develop ketosis or ketoacidosis within approximately 1 week [4].

Here, we describe the case of a patient with metastatic renal cell carcinoma (mRCC) who developed T1DM followed by hypophysitis during nivolumab therapy.

\section{Case presentation}

A 62-year-old Japanese man was referred to our department by the urology department because of hyponatremia. In 2003, he was diagnosed with right renal cancer, and he underwent right nephrectomy. Seven years later, a cancerous lesion was found in the right clavicle. Subsequent bone biopsy revealed that it was caused by metastasis of the renal cancer. He then underwent multiple rounds of chemotherapy (Fig. 1), and developed thyrotoxicosis after starting sunitinib treatment. Sunitinib treatment was discontinued, and the patient has been treated with the ICPI nivolumab $(3 \mathrm{mg} / \mathrm{kg})$ every 2 weeks since 2018.

After administration of the seventh cycle of nivolumab treatment, the patient complained of fatigue and dizziness, and was admitted to the urology department. On physical examination, the patient's blood pressure was 93/59 $\mathrm{mmHg}$, his pulse was 73 beats per minute, and his body temperature was $36.5^{\circ} \mathrm{C}$. His weight and height were $56.3 \mathrm{~kg}$ and $165 \mathrm{~cm}$, respectively. Results of the laboratory tests are shown in Table 1 . The patient had hyponatremia $(120 \mathrm{mmol} / \mathrm{l})$, with low levels of cortisol $(0.4 \mu \mathrm{g} / \mathrm{dl})$ and adrenocorticotropic hormone $(\mathrm{ACTH})$ $(6.64 \mathrm{pg} / \mathrm{ml})$, suggesting adrenal insufficiency. The serum levels of luteinizing hormone $(\mathrm{LH})(11.4 \mathrm{mIU} / \mathrm{ml})$ and prolactin (PRL) $(38.5 \mathrm{ng} / \mathrm{ml})$ were high, and those of insulin-like growth factor $(66 \mathrm{ng} / \mathrm{ml})$ were low. His symptoms and laboratory data suggested that the clinically suspected adrenal insufficiency was possibly due to pituitary adrenocortical hypofunction induced by nivolumab immunotherapy, despite the absence of changes in the size and density of the pituitary gland revealed on brain magnetic resonance imaging (MRI). The patient was started on steroid replacement therapy with $40 \mathrm{mg} / \mathrm{day}$ prednisolone. After starting steroid therapy, his physical condition improved rapidly. The dose of steroid was tapered and was finally maintained at $20 \mathrm{mg} /$ day of hydrocortisone. The patient became hyperglycemic because of the steroid treatment, which was managed with insulin. Because the ability to secrete insulin was unimpaired (C-peptide immunoreactivity [CPR] $2.37 \mathrm{ng} /$ $\mathrm{ml}$ ), he was started on liraglutide therapy, and nivolumab treatment was continued. After his symptoms subsided, the corticotropin-releasing hormone (CRH) load test was performed, which revealed that the serum ACTH level and cortisol response to CRH were very low (Table 2).

Following the 10th cycle of nivolumab treatment, the patient was referred to our department again because of high blood sugar levels. He was admitted to the hospital for suspected FT1DM associated with nivolumab treatment and was started on drip infusion therapy. On physical examination, the patient's blood pressure was

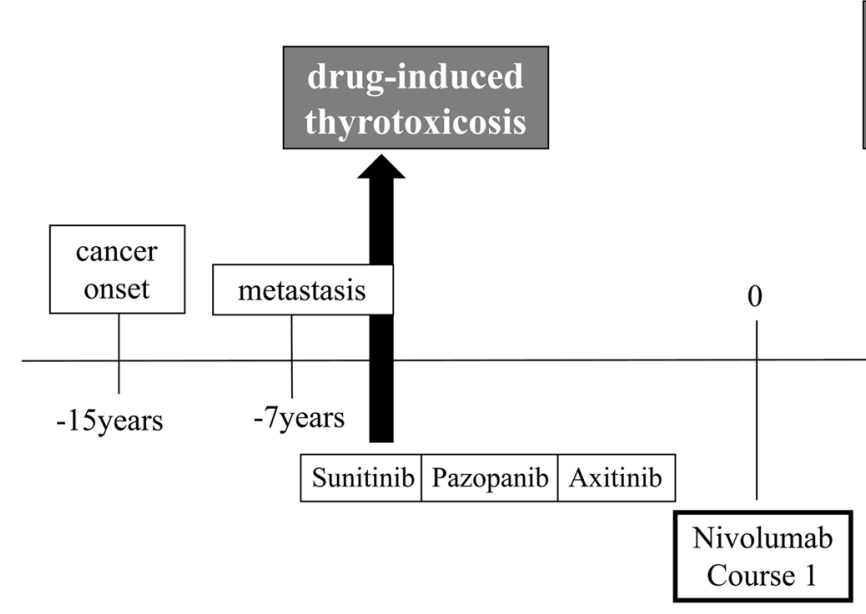

pituitary adrenocortical hypofunction

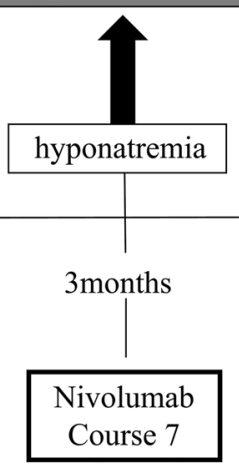

insulin-dependent diabetes
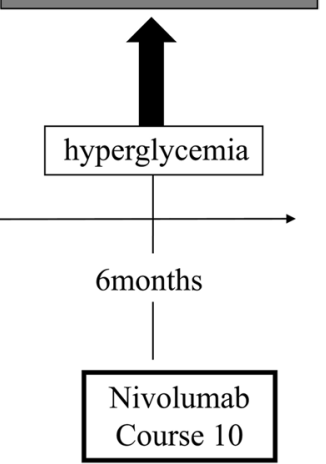

Fig. 1 The clinical course of multiple lines of chemotherapy and nivolumab 
Table 1 Laboratory results for the patient

\begin{tabular}{|c|c|c|}
\hline Variable & & Reference range \\
\hline \multicolumn{3}{|l|}{ Complete blood count } \\
\hline White blood cell count $(/ \mu l)$ & 5160 & $47.0-87.0$ \\
\hline Red blood cells $\left(\times 10^{4} / \mu l\right)$ & 383 & $370-490$ \\
\hline Hemoglobin (g/dl) & 9.8 & $11.0-15.0$ \\
\hline Hematocrit (\%) & 29.4 & $35.0-45.0$ \\
\hline Platelet count $\left(\times 10^{4} / \mu \mathrm{l}\right)$ & 30.4 & $15.0-35.0$ \\
\hline \multicolumn{3}{|l|}{ Biochemistry } \\
\hline Total protein (g/dl) & 6.1 & $6.5-8.2$ \\
\hline Albumin (g/dl) & 3.1 & $3.5-5.5$ \\
\hline Blood urea nitrogen (mg/dl) & 11.4 & $7.0-20.0$ \\
\hline Creatinine (mg/dl) & 1.46 & $0.5-1.0$ \\
\hline AST (U/I) & 38 & $10-35$ \\
\hline $\operatorname{ALT}(\mathrm{U} / \mathrm{l})$ & 13 & $5-40$ \\
\hline GGTP (U/I) & 17 & $0-30$ \\
\hline $\mathrm{Na}(\mathrm{mmol} / \mathrm{l})$ & 120 & $135-146$ \\
\hline $\mathrm{K}(\mathrm{mmol} / \mathrm{l})$ & 4.6 & $3.5-4.6$ \\
\hline $\mathrm{Cl}(\mathrm{mmol} / \mathrm{l})$ & 88 & $96-110$ \\
\hline Plasma osmolality (mOsm/kg) & 292 & $275-295$ \\
\hline \multicolumn{3}{|l|}{ Diabetes-related examination } \\
\hline Glucose (mg/dl) & 112 & 70-109 \\
\hline HbA1c (on admission) (\%) & 7.0 & $4.6-6.2$ \\
\hline Serum CPR (ng/ml) & 2.37 & $0.43-2.35$ \\
\hline \multicolumn{3}{|l|}{ Endocrinological examination } \\
\hline ACTH (pg/ml) & 6.64 & $7.2-63.3$ \\
\hline Cortisol ( $\mu \mathrm{g} / \mathrm{dl})$ & 0.4 & $2.3-19.4$ \\
\hline $\mathrm{GH}(\mathrm{ng} / \mathrm{ml})$ & 1.61 & $0.28-1.64$ \\
\hline IGF-1 (ng/ml) & 66 & $76-228$ \\
\hline PRL (ng/ml) & 38.5 & $4.3-13.7$ \\
\hline $\mathrm{LH}(\mathrm{mlU} / \mathrm{ml})$ & 11.4 & $0.57-12.07$ \\
\hline FSH (mlU/ml) & 7.6 & $0.95-11.95$ \\
\hline Testosterone (ng/ml) & 477.5 & $142.4-923.1$ \\
\hline $\operatorname{AVP}(p g / m l)$ & 0.8 & $0.3-4.2$ \\
\hline TSH $(\mu \mid \mathrm{I} / \mathrm{ml})$ & 2.14 & $0.35-4.94$ \\
\hline FT3 (pg/ml) & 3.71 & $1.71-3.71$ \\
\hline FT4 (ng/dl) & 1.03 & $0.70-1.48$ \\
\hline \multicolumn{3}{|l|}{ Urinalysis } \\
\hline U-Osmolality (mOsm/kg) & 178 & $767-1628$ \\
\hline U-Na $(\mathrm{mmol} / \mathrm{l})$ & 28 & \\
\hline U-K (mmol/l) & 17 & \\
\hline $\mathrm{U}-\mathrm{Cl}(\mathrm{mmol} / \mathrm{l})$ & 29 & \\
\hline U-Creatinine (mg/dl) & 29 & \\
\hline
\end{tabular}

AST aspartate aminotransferase, ALT alanine transaminase, GGTP gammaglutamyltransferase, $\mathrm{HbA1c}$ hemoglobin A1c, CPR C-peptide immunoreactivity, ACTH adrenocorticotropic hormone, GH growth hormone, IGF1 insulin-like growth factor, $P R L$ prolactin, $L H$ luteinizing hormone, $F S H$ follicle-stimulating hormone, AVP arginine vasopressin, TSH thyroid-stimulating hormone, FT3 free triiodothyronine, FT4 free thyroxin
Table 2 Laboratory results of corticotropin-releasing hormone tests

\begin{tabular}{lllll}
\hline Min & 0 & 30 & 60 & 90 \\
ACTH $(\mathrm{pg} / \mathrm{ml})$ & 1.0 & 1.0 & 1.0 & 1.0 \\
Cortisol $(\mu \mathrm{g} / \mathrm{dl})$ & 0.8 & 0.7 & 0.6 & 0.5 \\
\hline
\end{tabular}

ACTH adrenocorticotropic hormone

$148 / 72 \mathrm{mmHg}$, his pulse was 75 beats per minute, and his body temperature was $36.3{ }^{\circ} \mathrm{C}$. His mouth was dry and his skin turgor was poor, but he did not complain of any other symptoms. Although his plasma blood glucose levels were high $(601 \mathrm{mg} / \mathrm{dl})$, his hemoglobin A1c (HbA1c) levels were low (8.1\%), suggesting rapid progression of hyperglycemia. Abdominal computed tomography showed no pancreatic abnormality. Both his serum $\mathrm{C}$-peptide levels and his urinary C-peptide excretion levels were low. A glucagon stimulation test revealed insulin depletion, but he showed serum anti-glutamic acid decarboxylase (GAD) antibody negativity (details are outlined in Table 3). Laboratory investigations revealed hyperglycemia, but no acidosis or ketonuria. On the basis of these findings, we excluded FT1DM, and diagnosed the patient with insulin-dependent diabetes. The patient was treated with intravenous fluid infusion and continuous insulin infusion. His potassium and other electrolyte levels were within the normal range, and serum potassium fluctuations were within the normal range even after the introduction of insulin therapy. On the second day, he was switched to multiple daily injections of insulin therapy (Fig. 2). Since these treatments, his blood glucose levels have been stable and he has been treated with an additional 10 ICPI treatments for RCC for over a year.

\section{Discussion}

We presented the case of a patient with mRCC who developed thyroiditis on sunitinib treatment, which was changed to nivolumab therapy that caused hypophysitis and subsequently T1DM.

Sunitinib, a tyrosine kinase inhibitor (TKI), belongs to a class of drugs mainly used as targeted therapy in cancer treatment [5]. TKIs typically compete with adenosine triphosphate (ATP) for the binding site of particular oncogenic tyrosine kinases. By blocking the signaling pathways involved in the phosphorylation of many key proteins in signal transduction cascades, TKIs can depress tumor cell survival and proliferation. TKIinduced hypothyroidism is a highly complicated issue not only because of the unclear toxicological mechanisms, but also because of the different incidence of individual TKI drugs. While sunitinib is suspected of causing thyroid dysfunction more often than other TKIs, sorafenib 
Table 3 Laboratory results for the patient

\begin{tabular}{|c|c|c|}
\hline Variable & & Reference range \\
\hline \multicolumn{3}{|l|}{ Complete blood count (on admission) } \\
\hline White blood cell count $(/ \mu \mathrm{l})$ & 6500 & $47.0-87.0$ \\
\hline Red blood cells $\left(\times 10^{4} / \mu \mathrm{l}\right)$ & 425 & $370-490$ \\
\hline Hemoglobin (g/dl) & 11.6 & $11.0-15.0$ \\
\hline Hematocrit (\%) & 34.5 & $35.0-45.0$ \\
\hline Platelet count $\left(\times 10^{4} / \mu \mathrm{l}\right)$ & 36.5 & $15.0-35.0$ \\
\hline \multicolumn{3}{|l|}{ Biochemistry (on admission) } \\
\hline Total protein (g/dl) & 6.1 & $6.5-8.2$ \\
\hline Albumin (g/dl) & 2.8 & $3.5-5.5$ \\
\hline Blood urea nitrogen $(\mathrm{mg} / \mathrm{dl})$ & 31.7 & $7.0-20.0$ \\
\hline Creatinine (mg/dl) & 1.64 & $0.5-1.0$ \\
\hline Amylase (U/I) & 168 & $30-140$ \\
\hline Lipase (U/I) & 28 & $13-55$ \\
\hline Elastase-1 (ng/dl) & 110 & $0-300$ \\
\hline AST (U/l) & 25 & $10-35$ \\
\hline $\mathrm{ALT}(\mathrm{U} / \mathrm{l})$ & 20 & $5-40$ \\
\hline GGTP $(\mathrm{U} / \mathrm{I})$ & 76 & $0-30$ \\
\hline $\mathrm{Na}(\mathrm{mmol} / \mathrm{l})$ & 131 & $135-146$ \\
\hline $\mathrm{K}(\mathrm{mmol} / \mathrm{l})$ & 4.5 & $3.5-4.6$ \\
\hline $\mathrm{Cl}(\mathrm{mmol} / \mathrm{l})$ & 97 & $96-110$ \\
\hline \multicolumn{3}{|l|}{ Arterial blood gas analysis (room air) } \\
\hline $\mathrm{pH}$ & 7.44 & $7.35-7.45$ \\
\hline $\mathrm{pCO}_{2}(\mathrm{mmHg})$ & 37.2 & $32-45$ \\
\hline $\mathrm{pO}_{2}(\mathrm{mmHg})$ & 113 & $83-108$ \\
\hline Bicarbonate (mmol/l) & 24.7 & $21.2-27.0$ \\
\hline Anion gap (mmol/l) & 8.2 & $10.0-14.0$ \\
\hline \multicolumn{3}{|l|}{ Diabetes-related examination } \\
\hline Glucose (mg/dl) & 601 & 70-109 \\
\hline HbA1c (3 months before admission) (\%) & 7.0 & $4.6-6.2$ \\
\hline HbA1c (on admission) (\%) & 8.1 & $4.6-6.2$ \\
\hline Serum CPR (ng/ml) & 0.2 & $0.43-2.35$ \\
\hline Urinary CPR ( $\mu \mathrm{g} /$ day) & 5.3 & $17-181$ \\
\hline $\begin{array}{l}\text { CPR ( } 6 \text { min) during glucagon stimula- } \\
\text { tion test ( } 10 \text { th day) }(\mathrm{ng} / \mathrm{ml})\end{array}$ & 0.29 & $>0.5$ \\
\hline Urinary ketone & Negative & \\
\hline Anti-GAD antibody & Negative & \\
\hline
\end{tabular}

AST aspartate aminotransferase, ALT alanine transaminase, GGTP gammaglutamyltransferase, $p \mathrm{CO}_{2}$ partial pressure of carbon dioxide, $p \mathrm{O}_{2}$ partial pressure of oxygen, $\mathrm{HbA1c}$ hemoglobin $\mathrm{A} 1 \mathrm{c}, \mathrm{CPR} \mathrm{C}$-peptide immunoreactivity, $G A D$ glutamic acid decarboxylase

is believed to be less risky [6]. In our case, nivolumab was used in anticipation of further effects.

An estimated $20-30 \%$ of all patients with RCC have metastatic disease at the time of diagnosis. A recent study demonstrated the safety and acceptable outcomes of antiPD-1 therapy with nivolumab in patients with advanced RCC. Although nivolumab caused unique AEs, the AEs were treated promptly, and all except one was reversible. A recent study suggested that nivolumab is a reasonable therapeutic option for patients with mRCC after multiple lines of treatment [7]. However, future prospective studies with larger sample sizes are required to better understand the appropriate indications for nivolumab treatment in patients with RCC.

ICPI-related hypophysitis is frequently (up to $17 \%$ of cases) associated with the use of ipilimumab, an anti-CTLA-4 antibody, and patients with ipilimumabinduced hypophysitis typically experience headache, multiple anterior pituitary hormone defects, and reversible enlargement of the pituitary gland [8]. In contrast, hypophysitis is an extremely rare event $(<1 \%)$ in patients treated with other ICPIs, such as nivolumab [9]. The thyroid gland is the most commonly affected endocrine organ in patients under nivolumab treatment [1]. For example, only 18 hypophysitis cases $(0.9 \%)$ were identified in 10 studies that included approximately 2000 patients receiving nivolumab, pembrolizumab, or antiprogrammed death-ligand 1 (PD-L1) [2]. Furthermore, nivolumab-associated all-grade pituitary dysfunction occurred in only $0.5-0.9 \%$ of reported cases [8], and there are only three related case reports [10]. Radiographic pituitary enlargement was detected in only one of four cases, suggesting that morphologic changes in the pituitary may be less severe in patients with nivolumab-induced hypophysitis than that in patients with ipilimumab-induced hypophysitis. A previous report described dysfunction in the secretion of thyroidstimulating hormone (TSH), ACTH, LH/follicle-stimulating hormone (FSH), and PRL in $92.0 \%, 74.0 \%, 85.7 \%$, and $67.7 \%$ of ipilimumab-induced hypophysitis cases, respectively [8], whereas dysfunction in TSH secretion was only observed in two of four nivolumab cases, and no cases exhibited dysfunction in LH/FSH secretion. This information, along with the radiographic characteristics, suggests that the inflammatory process in the pituitary gland is much milder in nivolumab-induced hypophysitis than in ipilimumab-induced hypophysitis. In our case, there were no abnormal pituitary findings on MRI. As a side effect of nivolumab, hypophysitis was unusual but could be treated with symptomatically. In our case, even though there were side effects, nivolumab treatment was indispensable because it was related to life prognosis of mRCC.

Anti-PD-1 antibodies activate an anti-tumor immunologic response by abrogating PD-1-related $\mathrm{T}$ cell inhibition. They reportedly improve the prognosis of patients with several advanced malignancies [1]. Although nivolumab, an anti-PD-1 antibody, has improved the prognosis of and has become a popular treatment option for several advanced malignancies, various irAEs [11], including diabetes, have been reported. Although the precise mechanisms of nivolumab-induced T1DM are 
Total account of insulin (units /day)
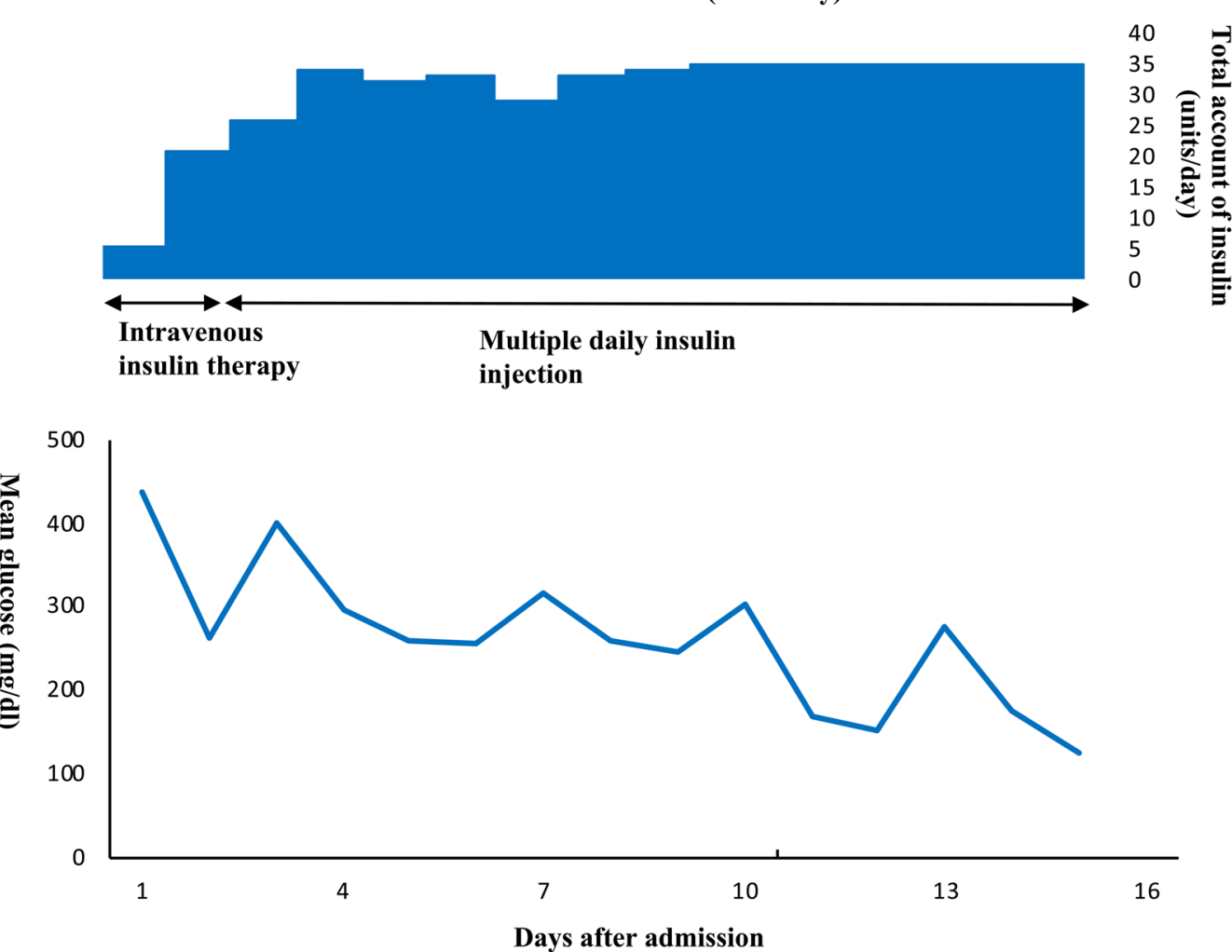

Fig. 2 The clinical course of insulin therapy. The upper panel shows the total insulin dose. The lower panel shows the mean glucose levels during the clinical course

not fully understood, activated CD8 $+\mathrm{T}$ cells have been speculated to evoke autoimmunity against pancreatic beta cells and to destroy them, resulting in insulin exhaustion [12]. Several reports have noted that cases of autoimmune diabetes, known as T1DM, have emerged in association with the use of the anti-PD-1 antibody therapies [5, 13]. Autoimmune diabetes is characterized by the development of an adaptive immune response against specific beta cell antigens. Longitudinal studies in patients have shown that certain autoantibodies, such as anti-indole 3 acetic acid (IAA), anti-islet cell antigen (ICA) 512, and anti-GAD65, define preclinical disease, as they are present in the serum for years before symptom onset. Likewise, half of the previously reported patients who developed insulin-dependent diabetes after anti-PD-1 therapy showed no detectable islet autoantibodies. The pathogenesis in these patients thus seems to differ at least partly from that of conventional autoimmune T1DM, which involves islet autoantibodies. Ansari et al. found no correlation between IAA levels and the development of diabetes with blockade of the PD-1/ PD-L1 pathway in mice, and some mice developed diabetes despite the apparent absence of autoantibodies [14].
In the present case, the patient tested negative for islet autoantibodies.

FT1DM has mainly been reported in East Asia, and it accounts for approximately $20 \%$ of T1DM cases with a classical acute-onset pattern in Japan [15]. According to the safety database, 20,600 patients in Japan were treated with nivolumab from July 4, 2014, to August 15, 2017, and 67 patients $(0.33 \%)$ developed "T1DM" or "FT1DM." Among these, 40 patients $(0.19 \%)$ were reported as having T1DM (10 patients had melanoma, 24 patients had non-small cell lung cancer, 3 patients had RCC, and the diagnosis for 3 patients was unknown), and 27 patients $(0.13 \%)$ were reported as having FT1DM (14 patients had melanoma, 12 patients had non-small cell lung cancer, and the diagnosis for 1 patient was unknown) [16]. Therefore, the incidence rate of T1DM related to nivolumab is 33 times as high as that of typical FT1DM. In addition, there was no particular relationship between primary tumors and anti-PD-1 antibody-related T1DM.

Acute-onset T1DM was diagnosed based on the criteria set by the Committee of the Japan Diabetes Society (JDS) [17]. Briefly, among patients who developed diabetic ketosis or ketoacidosis within 3 months after 
the onset of hyperglycemic symptoms and patients who needed insulin treatment continuously after their diabetes diagnosis, patients with islet autoantibodies were diagnosed as having "acute-onset T1DM (A1DM) (autoimmune)," and those whose endogenous insulin secretion was depleted (fasting serum C-peptide immunoreactivity $<0.6 \mathrm{ng} / \mathrm{ml}$ ) without verifiable islet autoantibodies were diagnosed as having "acute-onset type 1 diabetes." The diagnosis of FT1DM was based on the following criteria from the Report of the JDS Committee on type 1 diabetes mellitus research: (1) ketosis or ketoacidosis within 1 week after the onset of hyperglycemic symptoms, (2) urinary C-peptide level below $10 \mu \mathrm{g} /$ day or fasting serum C-peptide level below $0.3 \mathrm{ng} / \mathrm{ml}$ and serum C-peptide level below $0.5 \mathrm{ng} / \mathrm{ml}$ after glucagon injection or meal load soon after the onset of disease, and (3) plasma glucose (PG) level above $288 \mathrm{mg} / \mathrm{dl}$ and HbA1c below 8.7\% at the first visit [18]. Although this case was diagnosed as A1DM on the basis of diagnostic criteria, it is very similar to FT1DM on the basis of the clinical course. Among the 35 published cases of nivolumab-induced T1DM, 17 patients were reported to be positive and 17 negative for islet autoantibodies, and the islet autoantibody levels were not measured in one patient. As in the present case, rapidly progressive T1DM was observed in eight patients without any detectable autoimmune islet antibodies; however, those patients were human leukocyte antigen (HLA)-type-positive, which resulted in sensitivity to acute-onset T1DM. Nivolumab may likely induce rapidly progressive T1DM through an autoimmune mechanism independent of conventional pancreatic islet cell-related autoantibodies [19].

The pathogenesis of FT1DM is influenced by genetic and environmental factors. Among genetic factors, HLA class II genes are strongly associated with susceptibility to progression to FT1DM. The HLA DR4-DQ4 haplotype is common in Japanese individuals but is rare in the Caucasian populations and may contribute to the different incidence rates of FT1DM between the these two populations. Imagawa et al. reported that the frequency of HLA-DR4, but not HLA-DR9, was significantly higher in FT1DM, whereas the frequencies of HLA-DR1, HLA-DR2, HLA-DR5, and HLADR8 were significantly lower. In contrast, DR9 but not DR4 was more frequent, and DR2 was extremely rare in T1DM [20]. Additionally, a recent report indicated that the frequencies of the DRB1*04:05-DQB1*04:01 and DRB1*09:01-DQB1*03:03 haplotypes were significantly higher and those of the DRB1*01:01-DQB1:05:01, DRB1:15:02-DQB1"06:01 and DRB1*08:03-DQB1"06:01 haplotypes were significantly lower in patients with FT1DM than in control subjects [21]. In our study, informed consent could not be obtained, and an HLA search could not be performed, but if an HLA search had been performed, it would have been a predictor of the onset of T1DM due to nivolumab. We believe that an HLA search should be performed in the future in patients who use nivolumab.

There are a few reports of patients who developed both hypophysitis and T1DM after being treated with an ICPI [22]. Several studies showed that panhypopituitarism induced a remarkable reduction in insulin doses in patients with T1DM $[22,23]$. A complete amelioration of diabetes induced by adrenal insufficiency was reported in patients with type 2 diabetes [24], but it has never been reported in a patient with T1DM with decreased insulin secretory capacity to an insulindependent level as observed in our patient.

\section{Conclusions}

ICPI treatment is expected to increase in the future. There may be cases in which their use for cancer treatment is inevitable despite the side effects. As long as treatment with ICPI continues, multiple side effects can be expected in some cases. It is important to carefully observe the side effects that occur during ICPI treatment and to provide appropriate treatment for each side effect.

\section{Abbreviations \\ ICPIs: Immune checkpoint inhibitors; irAEs: Immune-related adverse events; T1DM: Type 1 diabetes mellitus; PD-1: Anti-programmed cell death protein 1; CTLA-4: Anti-cytotoxic T lymphocyte-associated antigen-4; mRCC: Metastatic renal cell carcinoma; $\mathrm{CRH}$ : Corticotropin-releasing hormone; TKI: Tyrosine kinase inhibitor; A1DM: Acute-onset T1DM.}

\section{Acknowledgements}

We would like to acknowledge the patient for allowing his case to be published.

\section{Authors' contributions}

$\mathrm{FK}, \mathrm{HI}$, and KM designed the study, and wrote the initial draft of the manuscript. TK, JL, and TS contributed to analysis and interpretation of data, and assisted in the preparation of the manuscript. KF, TI, SS, NB, and SJ contributed to data collection and interpretation, and critically reviewed the manuscript. All authors read and approved the final manuscript.

\section{Funding}

This work was supported by KAKENHI (Grants-in-Aid for Scientific Research) Grant number 18K08518.

\section{Availability of data and materials Not applicable.}

\section{Ethics approval and consent to participate}

The study was approved by the ethics committees at Kagawa University (ID:2019-268). Written informed consent for publication of this paper was obtained from the patient.

\section{Consent for publication}

Written informed consent was obtained from the patient for publication of this manuscript and accompanying images. A copy of the written consent is available for review by the Editor-in-Chief of this journal. 


\section{Competing interests}

The authors declare that they have no competing interests.

\section{Author details}

${ }^{1}$ Department of Endocrinology and Metabolism, Faculty of Medicine, Kagawa University, 1750-1, Miki-cho, Kita-gun, Takamatsu, Kagawa 761-0793, Japan. ${ }^{2}$ Present Address: Department of Internal Medicine, Sanuki Municipal Hospital, 387-1, Sangawa-cho, Sanuki, Kagawa 769-2393, Japan.

Received: 8 May 2020 Accepted: 28 December 2020

Published online: 23 April 2021

\section{References}

1. Topalian S, Hodi F. Safety, activity, and immune correlates of anti-PD-1 antibody in cancer. N Engl J Med. 2012;366:443-2454.

2. Torino F, Corsello SM, Salvatori R. Endocrinological side-effects of immune checkpoint inhibitors. Curr Opin Oncol. 2016;28:278-87.

3. Joshi MN, Whitelaw BC, Palomar MTP, Wu Y, Carroll PV. Immune checkpoint inhibitor-related hypophysitis and endocrine dysfunction: clinical review. Clin Endocrinol. 2016:85:331-9.

4. Hughes J, Vudattu N, Sznol M, et al. Precipitation of autoimmune diabetes with anti-PD-1 immunotherapy. Diabetes Care. 2015;38:e55-7.

5. Yamamoto K, Mizumoto A, Nishimura K, et al. Association of toxicity of sorafenib and sunitinib for human keratinocytes with inhibition of signal transduction and activator of transcription 3 (STAT3). PLoS ONE. 2014;9:e102110.

6. Ahmadieh H, Salti I. Tyrosine kinase inhibitors induced thyroid dysfunction: a review of its incidence, pathophysiology, clinical relevance, and treatment. Biomed Res Int. 2013:2013:725410.

7. Numakura K, Horikawa Y, Kamada S, et al. Efficacy of anti-PD-1 antibody nivolumab in Japanese patients with metastatic renal cell carcinoma: a retrospective multicenter analysis. Mol Clin Oncol. 2019;11:320-4.

8. Faje A. Immunotherapy and hypophysitis: clinical presentation, treatment, and biologic insights. Pituitary. 2016;19:82-92.

9. Eigentler TK, Hassel JC, Berking C, et al. Diagnosis, monitoring and management of immune-related adverse drug reactions of anti-PD-1 antibody therapy. Cancer Treat Rev. 2016;45:7-18.

10. Okano Y, Satoh T, Horiguchi K, et al. Nivolumab-induced hypophysitis in a patient with advanced malignant melanoma. Endocr J. 2016;63:905-12.

11. Boutros C, Tarhini A, Routier E, et al. Safety profiles of anti-CTLA-4 and anti-PD-1 antibodies alone and in combination. Nat Rev Clin Oncol. 2016:13:473-86.
12. Sznol M, Postow MA, Davies MJ, et al. Endocrine-related adverse events associated with immune checkpoint blockade and expert insights on their management. Cancer Treat Rev. 2017;58:70-6.

13. Gaudy C, Clévy Ć, Monestier S, et al. Anti-PD1 pembrolizumab can induce exceptional fulminant type 1 diabetes. Diabetes Care. 2015;38:e182-3.

14. Ansari MJI, Salama AD, Chitnis T, et al. The Programmed Death-1 (PD-1) Pathway Regulates Autoimmune Diabetes in Nonobese Diabetic (NOD) Mice. J Exp Med. 2003;198:63-9.

15. Imagawa IA, Hanafusa $T$, Uchigata $Y$, et al. Fulminant type 1 diabetes: a nationwide survey in Japan. Diabetes Care. 2003;26:2345-52.

16. Baden MY, Imagawa A, Abiru N, et al. Characteristics and clinical course of type 1 diabetes mellitus related to anti-programmed cell death-1 therapy. Diabetol Int. 2019;10:58-66.

17. Kawasaki E, Maruyama T, Imagawa A, et al. Diagnostic criteria for acuteonset type 1 diabetes mellitus (2012): Report of the committee of Japan diabetes society on the research of fulminant and acute-onset type 1 diabetes mellitus. J Diabetes Investig. 2014;5:115-8.

18. Imagawa A, Hanafusa T, Awata T, et al. Report of the Committee of the Japan Diabetes Society on the Research of Fulminant and Acute-onset Type 1 Diabetes Mellitus: New diagnostic criteria of fulminant type 1 diabetes mellitus (2012). J Diabetes Investig. 2012;3:536-9.

19. Sakaguchi S, Ashida K, Yano S, et al. A case of nivolumab-induced acuteonset type 1 diabetes mellitus in melanoma. Curr Oncol. 2019;26:e115-8.

20. Imagawa A, Hanafusa T, Uchigata Y, et al. Different contribution of class II HLA in fulminant and typical autoimmune type 1 diabetes mellitus. Diabetologia. 2005;48:294-300.

21. Tsutsumi C, Imagawa A, Ikegami H, Makino H, Kobayashi T, Hanafusa T. Class II HLA genotype in fulminant type 1 diabetes: a nationwide survey with reference to glutamic acid decarboxylase antibodies. J Diabetes Investig. 2012;3:62-9.

22. Sum M, Garcia FV. Immunotherapy-induced autoimmune diabetes and concomitant hypophysitis. Pituitary. 2018;21:556-7.

23. Matoba K, Mitsuishi S, Hayashida S, et al. Hypopituitarism possibly due to lymphocytic hypophysitis in a patient with type 1 diabetes. Intern Med. 2014;53:1961-4.

24. Pramanik S, Bhattacharjee R, Mukhopadhyay P, et al. Lesson of the month 2: Houssay phenomenon-hypopitutarism leading to remission of diabetes. Clin Med (Lond). 2016;16:294-6.

\section{Publisher's Note}

Springer Nature remains neutral with regard to jurisdictional claims in published maps and institutional affiliations.
Ready to submit your research? Choose BMC and benefit from:

- fast, convenient online submission

- thorough peer review by experienced researchers in your field

- rapid publication on acceptance

- support for research data, including large and complex data types

- gold Open Access which fosters wider collaboration and increased citations

- maximum visibility for your research: over 100M website views per year

At BMC, research is always in progress.

Learn more biomedcentral.com/submissions 